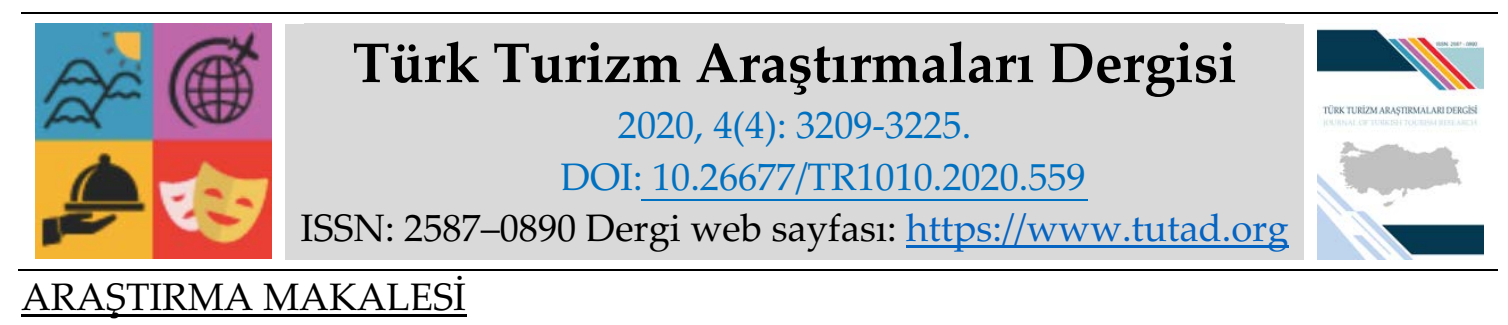

\title{
Personel Güçlendirmenin Rekabet Zekâsına Etkisi: Turizm Sektöründe Bir Araştırma
}

Dr. Öğr. Üyesi Seda KAYAPALI YILDIRIM, Kafkas Üniversitesi, Sarıkamış Turizm Fakültesi, Kars, e-posta: seda.yildirim@kafkas.edu.tr ORCID: https://orcid.org/0000-0003-4438-2445

\section{Öz}

Çalkantılı çevrede işletmeler, hayatta kalabilmek adına yoğun bir mücadele vermektedir ve bu mücadele içerisinde rekabet üstünlüğünü elde edebilmek için insan kaynakları örgütlerin en önemli unsurlardan birisidir. Özellikle güçlendirilmiş personel, doğru stratejik kararları alabilmekte ve örgütsel etkinliği yükseltebilmektedir. Tüm bunlar gerçekleşirken örgüt içi ve dışı bilgiye ve iletişimin yüksek olduğu güvenilir bir yapıya ihtiyaç duyulmaktadır. Özellikle rakiplerden ve diğer çevre unsurlarından elde edilen doğru bilgiye zamanında erişilebilmeli ve işletmenin stratejik eylemleri buna göre planlanmalıdır. Diğer yandan turizm sektörü Türkiye için katma değer üreten ve şiddetli rekabetin olduğu bir sektördür. Bu sektörde faaliyet gösteren otel işletmelerinin personel güçlendirme ve rekabet zekâsı düzeylerini belirlemek önemlidir. Ayrıca olumlu örgütsel uygulamalarıyla personel güçlendirme rekabet zekâsı için destekleyici bir ortam sunmaktadır. Bu nedenle araştırmada personel güçlendirmenin rekabet zekâsına olan etkisini araştırmak amaçlanmıştır. Bu ana amaç doğrultusunda turizm sektöründe faaliyet gösteren otellerde çalışan 400 işgörenden anket yöntemiyle veri toplanmıştır. Elde edilen verilere uygulanan Yapısal Eşitlik Modellemesi sonuçlarına göre yapısal güçlendirme; rekabet kültürü, örgütsel katılım ve bilgi tasarlamayı anlamlı ve olumlu etkilerken, farkındalık, odaklanma ve kıyaslama alt boyutlarını anlamlı olarak etkilememiştir. Diğer yandan psikolojik güçlendirme; rekabet kültürü, örgütsel katılım, bilgi tasarlama, farkındalık, odaklanma ve kıyaslama alt boyutlarının tümünü anlamlı ve olumlu olarak etkilemiştir.

Anahtar Kelimeler: Stratejik Yönetim, Personel Güçlendirme, Rekabet, Rekabet Zekâsı, Rekabet Üstünlüğ̈̈.

Makale Gönderme Tarihi: 11.07.2020

Makale Kabul Tarihi: 09.10.2020

\section{Önerilen Atıf:}

Kayapalı Yıldırım, S. (2020). Personel Güçlendirmenin Rekabet Zekâsına Etkisi: Turizm Sektöründe Bir Araştırma, Türk Turizm Araştırmaları Dergisi, 4(4): 3209-3225.

(C) 2020 Türk Turizm Araştırmaları Dergisi. 


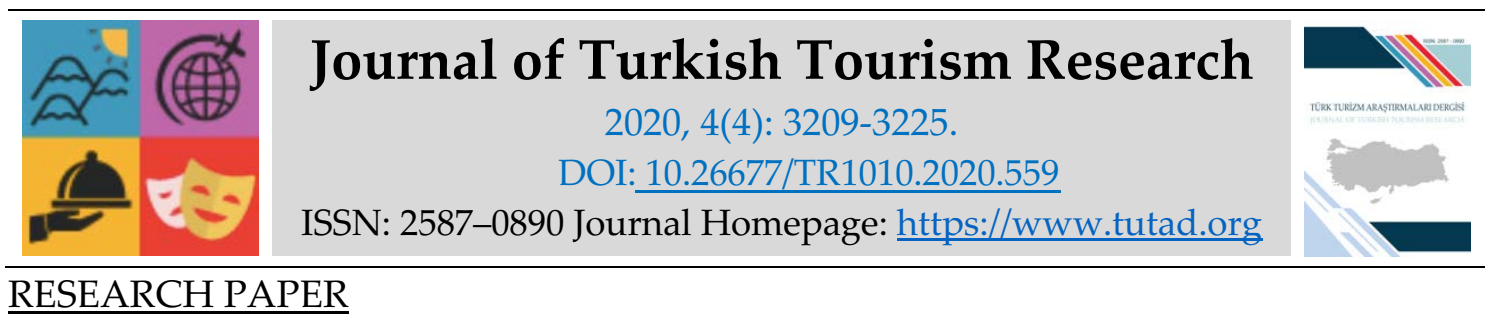

\title{
The Effect of Empowerment on Competition Intelligence: A Research in Tourism Sector
}

Assistant Prof. Dr. Seda KAYAPALI YILDIRIM, Kafkas University, Faculty of Tourism, Kars, email: seda.yildirim@kafkas.edu.tr

ORCID: https://orcid.org/0000-0003-4438-2445

\begin{abstract}
Enterprises struggle intensely in a turbulent environment to survive and human resources are one of the most important elements of organizations in order to achieve competitive advantage. Especially empowered staff can make the right strategic decisions and improve organizational effectiveness. While all this is happening, internal and external information and a reliable structure with high communication are needed. Especially, accurate information obtained from competitors and other environmental elements should be accessed in a timely manner and the strategic actions of the enterprise should be planned accordingly. On the other hand, tourism industry that generates added value for Turkey and it is a sector where there is fierce competition. It is important to determine the personnel empowerment and competitive intelligence levels of the hotel businesses operating in this sector. In addition, staff empowerment with its positive organizational practices provides a supportive environment for competitive intelligence. For this reason, it was aimed to investigate the effect of staff empowerment on competition intelligence. In line with this main purpose, data was collected from the 400 employees working in the hotels operating in the tourism sector by means of a survey method. According to the results of Structural Equation Modeling applied to the obtained data, structural empowerment significantly affected culture, organizational participation and information design, and did not significantly affect awareness, focus and comparison sub-dimensions. On the other hand, competition culture, organizational participation, knowledge design, awareness, focus and comparison all of the sub-dimensions have been significantly and positively affected by psychological staff empowerment.
\end{abstract}

Keywords: Strategic Management, Empowerment, Competition, Competitive Intelligence, Competitive Advantage.

Received: 11.07 .2020

Accepted: 09.10.2020

Suggested Citation:

Kayapalı Yıldırım, S. (2020). The Effect of Empowerment on Competition Intelligence: A Research in Tourism Sector, Journal of Turkish Tourism Research, 4(4): ?-?.

(C) 2020 Türk Turizm Araştırmaları Dergisi. 


\section{Gíriş}

Birçok örgüt sürekli olarak şiddetli rekabet baskısı altında çevre ile dinamik bir ilişki içerisinde hareket etmektedir Dinamik bir çevrede ise rekabetle uzun vadede başa çıkabilmenin anahtarı bilgidir ve bu durum uluslararası düzlemde fikir birliğiyle kabul edilmiştir. Üstelik bu fikir birliği bilginin gelişi güzel sağlanmasından ziyade sistematik bir biçimde elde edilmesi, yorumlanması, saklanması, paylaşılması, çoğaltılması ve stratejik karar verme mekanizmalarında kullanılması üzerinde de yoğunlaşmıştır. Murphy'e (2005) göre örgütler çevresinde gerçekleşen teknolojik gelişmeleri takip etmeli, alışkanlıklarını izlemeli ve genel olarak rekabet iklimine hazır olmalıdır. Aslında bu ifade örgütlerin davranışlarına uygun tahminler oluşturmak için çevreden sistematik olarak etik yollarla bilginin elde edilme ve yorumlanma çabası olan rekabet zekâsı kavramını tanımlamaktadır (Fleisher, 2008). Kotler ve Keller'e (2003) göre vasatın altı işletmeler rakiplerini görmezden gelirken ortalama şirketler rakiplerinden kopya çeker buna karşın başarılı işletmeler rakiplerini de yönetir. Rakipleri yönetebilmek ise ancak rekabet zekâsına sahip işletmelerin elde ettiği sistemli bilgi aracılığıyla onların eylemlerini öngörmek ve tepki vermek ile sağlanabilir.

Rekabetçi bir zekâ üretebilmek için ilk olarak örgüt içinden veya dışından uzmanların elde ettiği istihbaratı örgüte kazandıracak bir yapı gerekmektedir. İkinci aşamada rakiplerin endüstri raporları, mali tablolar veya faaliyet raporları gibi halka açı bilgilerinden bilgi elde edilmesini kapsar. Son aşamada ise tüm bu bilgileri anlamlandırmak için yapbozun farklı parçalarını bir araya getirmek ve bütün resme odaklanmak vardır (Jaworski vd., 2002). Söz konusu zekâyı üretecek unsurları bir araya getirecek örgütsel uygulamalara ve buna bağlı hareket eden nitelikli insan kaynağına ihtiyaç duyulmaktadır. Bu nedenle personel güçlendirmenin rekabetçi zekâyı oluşturacak bir zemin hazırlayacağı düşünülmektedir. Conger ve Kanungo (1988) işletmelerde rekabet üstünlüğünü azaltan unsurların tespit edilmesi ve bu unsurların yok edilerek örgüt üyelerine özgüven ve motivasyon kazandırma sürecini personel güçlendirme olarak tanımlamıştır. Tüm bu dayanaklardan hareketle rekabetçi bir zekâ oluşturabilmek için uygun örgüt yapısını ortaya koymak önemlidir.

Rekabet zekâsı uluslararası araştırmalara uzun yıllardır konu olsa bile Türkiye'de oldukça az araştırma mevcuttur. Özellikle turizm sektörünün ülke ekonomisine yaptığı katma değer düşünüldüğünde bu sektörün rekabetçi özelliklerini ortaya koymak önemli bir katkı sunacaktır. Turizm işletmeleri uzun yılların verdiği bilgi birikimine bağlı olarak şiddetli bir rekabetin içerisinde yaşam savaşı vermektedir. Dolayısıyla bu hizmet işletmelerinde rekabet zekâsını yükseltecek insan kaynakları için uygun örgütsel ortamın oluşturulması önemli olan bir diğer husustur. Tüm bu sebepler nedeniyle personel güçlendirmenin rekabet zekâsına olan etkisini tespit etmek bu araştırmanın esas amacını oluşturmaktadır. Bu doğrultuda önce kavramlar açıklanarak aralarındaki ilişkilere yer verilmiş ve hipotezler oluşturulmuştur. Ardından yapılan araştırma ile bulgulara yer verilmiş ve sonuçlar tartışılmıştır.

\section{KAVRAMSAL ÇERÇEVE}

\section{Rekabet Zekâsı}

Yaklaşık 20 yıldır araştırmacıların ilgisini çeken ve önemli bir stratejik üstünlük sağlayan rekabet zekâsı, işletme yöneticileri tarafından adı konulmamış bir şekilde çok daha uzun yıllardır kullanılmaktadır. Köseoğlu ve diğerleri (2016) Amerika Birleşik Devletlerindeki otellerin yöneticileri üzerinde rekabet zekâsı farkındalığı üzerine bir araştırma yapmış ve kavramın bilinirliği oldukça düşük çıkmıştır. Aslında işletme hayatında kullanılan rekabet zekâsının farkındalığını artırmak işletmelerin konuya daha bilinçli yaklaşması açısından önemlidir. 
Sürdürülebilir bir rekabet avantajı elde etmenin en iyi yolu rakiplerin eylemlerini belirleme, analiz etme ve bunlara karşı davranış geliştirme yeteneğinden geçmektedir (Hunt ve Morgan, 1995). Bu yetenek ise rekabet zekâsı olarak tanımlamaktadır ve pazar (veya pazarlama) istihbaratı, rekabetçi istihbarat, iş zekâsı, rekabet istihbaratı ve diğer terimler çeşitli zamanlarda aşağı yukarı aynı kavramı tanımlamak için kullanılmıştır (Venter ve Tustin, 2009: 89). Pellissier ve Nenzhelele'ye (2013) göre rekabet zekâsı, iç veya dış ortamdan rekabetçi bilgiyi planlı olarak etik ve yasal yollardan toplamak, işlemek ve analiz etmek suretiyle eyleme geçirilebilir zekâ üreten ve yayan süreç veya uygulamadır. Karar vericilere, karar vermede yardımcı olmak ve işletmeye sürdürülebilir rekabet üstünlüğü sağlamak için kullanılmaktadır. Rekabet zekâsı kavramı ile ilgili olarak yönetsel kararları almak için gereken iç ve dış istihbaratı sağlamak kadar yaygın kabul edilen başka bir terim yoktur (Du Toit, 2015: 15). Ayrıca rekabet zekâsı disiplinler arası alanlarda çalışılan bir kavramdır. Kavramı işletme yönetimi, pazarlama yönetimi, bilgi yönetimi ve stratejik yönetim gibi disiplinler ve diğer bazı disiplinler araştırmaktadır (Solberg ve Søilen, 2010: 201; Gabriel ve Adiele 2012: 27). Dolayısıyla kavramın tanımıyla ilgili net bir fikir birliği yoktur.

Araştırmacılar, rekabet zekâsının uygulanmasıyla ilgili çok çeşitli modeller ileri sürmektedir. Endüstrilere göre farklılık gösterse de bu modellerin birçoğunun özellikleri ortaktır. Birçok modele göre ilk olarak rakiplerin tanınması sürecin başlangıç noktasını oluşturmaktadır. Ardından sırasıyla rakipler hakkında elde edilmesi gereken anahtar bilgiler ve analiz yöntemleri belirlenirken elde edilecek bilgini kaynağının ortaya konulması gerekmektedir. Süreç sağlanan verilerin analiz edilmesi ve karşılaştırma yapılmasıyla devam eder. Bu vesileyle rakiplerin geleceğe yönelik eylemleri tahmin edilir ve karşı tepkiler planlanır. Son aşamada geri bildirimlerle süreç sürekli olarak güncellenir ve yeniden değerlendirme döngüsü oluşturulur (Keiser, 1987; Viviers, Saayman ve Muller, 2005: 578-580). Rekabet zekâsı çabaları gelişi güzel oluşturulamaz aksi takdirde bilgi kargaşası içerisinde gösterilen emeğin karşılığı alınamaz ve örgütler bu bilgi kargaşasından olumsuz etkilenebilir (Dutka, 1999). Örgütlerde bu çabaların belirli bir sistematik içerisinde ilerlemesini teşvik edecek kültür, mutlaka geliştirilmelidir. Personel güçlendirme böyle bir kültürel değişim için ideal bir uygulama olabilir.

\section{Personel Güçlendirme}

Ripley'e göre (1990) personel güçlendirme üç farklı çerçeveden değerlendirilebilir. Bunlardan ilki, personel güçlendirmenin kavram şeklinde ele alınarak bazı yetkilerin ve yönetsel mekanizmaların özellikle de karar verme ve onamanın personele devredilmesidir. İkincisi, felsefi bir bakış açısıyla değerlendirilerek örgütte paylaşılan vizyona uygun olacak şekilde üyelerin bireysel ve örgütsel amaçlara ulaşmak için imkân elde etmesi olarak ifade edilebilir. Üçüncüsü, örgütsel davranış içinde ele alınan kavram başarıyı sağlamak için personelin bir yapı altında toplanması, bilgi ve becerilerinin en üst seviyeye getirilmesi ve geliştirilmesidir (Ripley ve Ripley, 1990). Aslında temelleri çok eskilere dayanan kavram 60'larda iş zenginleştirme, 70 'lerde endüstriyel demokrasi, 80'lerde kararlara katılım ve nihai olarak 80'lerin sonu ile personel güçlendirmeye evirilmiştir (Wilkinson, 1998). Personel güçlendirme sadece teorik bir altyapı olmaktan çok daha ötede bir uygulamadır ve pratikte birtakım unsurları barındırması gerekmektedir. Bu unsurlar; bilgi paylaşımı, kararlara katılım, sorumluluk, ödüllendirme, takım çalışması, esneklik, yönetim desteği, kaynaklara ulaşma, eğitim, geliştirme, açık iletişim ve güven gibi örgütsel olguları içermektedir (Block, 1987; Margulles vd., 1995; DeCarlo, 2004; Boone ve Kurtz, 2013). Bu kavramların her biri kendi içerisinde personel güçlendirmeden farklı kavramlar olsalar da bir araya geldiklerinde güçlendirme uygulamasını ortaya çıkarmaktadırlar. 
Personel güçlendirme genel olarak iki boyutta ele alınmaktadır. İlki temelinde sosyal güç ve sosyal değişimin olduğu, ast ve üst arasında güç paylaşımının bulunduğu yapısal güçlendirmedir (Spreitzer, 2005). Yapısal güçlendirme iletişimin sağlanması ile bilginin kaynak ve destek oluşturması sonucunda ortaya çıkmaktadır (Li vd., 2008). İkinci boyut ise psikolojik güçlendirmedir ve yönetimsel uygulamalardan ziyade çalışanların algıları ön plandadır. Çalışanların öz-yeterliliklerinin, motivasyonlarının ve güvenlerinin artırılması önemlidir (Thomas ve Velthouse, 1990). Psikolojik olarak güçlendirilmiş işgörenler örgütsel rolleri ile uyum içerisinde çalışabilirler.

Personel güçlendirme iyi bir eğitim ve bu eğitime paralel olarak sağlanan gelişim ile beraber personelin kararlara katılımını sağlayarak örgütte en doğru stratejik kararların alınmasını sağlar. Ayrıca motivasyonun yükselmesini hedefleyen güçlendirme, personelin müşteri isteklerine daha iyi cevap verebilmesini ve örgütsel amaçlara daha çok odaklanılmasını da sağlamaktadır (Cook vd., 1997). Takım halinde çalışan güçlendirilmiş personel hem riski hem de sorumluluğu paylaşır. Bu vesileyle açık iletişim oluşur ve bilginin paylaşıldığı güvenilir bir ortam ortaya çıkar (Sigler ve Pearson, 2000). Buna karşın yöneticilerin rollerini değiştirmek istememesi, maliyetlerin yüksekliği, yeteri kadar eğitim verilememesi, her işletmede işlevsel olmaması gibi uygulama sorunlarından kaynaklanabilecek zayıf yönlere de dikkat etmek gerekmektedir (Koçel, 2011: 418). Personel güçlendirmenin doğru uygulanabilmesi için özellikle yöneticilerin geleneksel yönetici yapısına bürünmekten çok bir koordinatör görevi üstlenerek örgütü paylaşılan vizyona yönlendirmesi gerekmektedir.

\section{Kavramlar Arası İlişkiler}

Kumar ve diğerlerine (2019) göre dinamik bir iş ortamında bilgiye anlam verme aşaması iki ana nedenden dolayı karmaşık bir bulmacaya dönüşür. İlk olarak, dış kaynaklardan elde edilen rekabetçi bilgiler (anket verileri, danışman raporları, sektör raporları ve yıllık raporlar) genellikle geçerlilik, doğruluk ve güvenirlikten yoksundur, böylece toplanan bilgilerden anlamlı yorumlar elde etmek için zorluklar meydana gelmektedir. Diğer yandan ikincil bilgi kaynakları sıklıkla birbiriyle çelişir ve bunun sonucu olarak örgüt içerisinde çelişkili istihbarata yol açar ve sonuçlardan çıkarım yapılması zorlaşır. İkinci olarak rekabetçi ortam gelişmeye devam ettikçe rekabetçi bilgilerin sürekli güncellenmesi gerekmektedir. Dinamik bir ortamda yöneticilerin kaynakları uygun bir şekilde (yeniden) tahsis etmek için rakip yapısı hakkındaki yorumlarının sık sık güncellenmesi önemlidir (Gelb vd., 1991; Xu ve Kaye, 2009; Manyika vd., 2011; Guo vd., 2014). Ancak sürekli güncelleme zaman alıcı ve maliyetli olabilir. Ayrıca hiç hesaba katılmayan makro faktörlerde sürekli gün yüzüne çıkmaktadır. Bu olumsuzlukları en aza indirebilmek için tüm çalışanların sıkı sıkıya bağlandığı, paylaşılan ortak değerler doğrultusunda hareket eden ve rekabet zekâsı çabalarını sahiplenici bir örgüt kültürü oluşturmalıdır. Öyle ki Miller'e (2000) göre örgüt içerisinde her kademeden işgörenin bilgiyi elde edebileceği, çoğaltabileceği ve karar vericilerin bu bilgilerden yararlanabileceği örgüt kültürü ve örgütsel bir yapı rekabet zekâsı sürecinde başarının anahtarıdır (Miller, 2000). Bu noktadan hareketle; paylaşılan vizyon yaratan, sorumluluk devri veren, iyi bir iletişimle ve takım çalışmasıyla güven ortamı oluşturan, kararlara katılımı destekleyen ve bununla beraber eğitim ve geliştirme metotlarıyla isabetli kararlar verilmesini sağlayan personel güçlendirmenin (Erstad, 1997) bu kültürel ortamı ve yapıyı destekleyebileceği düşünülebilir. Özgen ve Türk'e (1997) göre bazı işletmelerde daha az, bazı işletmelerde daha yüksek derecede personel güçlendirme uygulamaları mevcuttur. Daha açık bir ifadeyle tamamen "güçlendirilmiş" veya tamamen "güçlendirmeden uzak" bir örgütten bahsetmek mümkün değildir (Emet, 2006). Dolayısıyla personel güçlendirme uygulamalarındaki bu değişim düzeyi rekabetçi zekâ düzeylerini de değiştirecektir. Güçlendirilmiş personel, aldığ 
düzenli eğitimin vasıtasıyla iç veya dış kaynaklardan elde ettiği bilgiyi, güvenilir hale getirme ve doğru yorumlama yeteneği ile donatılır.

Kavramlar arası ilişkileri ve literatürü genel olarak toparlamak gerekirse personel güçlendirme; çalışanlar arasında paylaşılan ortak vizyon, takım çalışması, kararlara katılım, doğru kararları verebilmek için verilen sürekli eğitim, bilgiyi elde etme çabası ve oluşturulan güven ortamı ile bilgi paylaşımı gibi uygulamalar sayesinde rekabet zekasını olumlu olarak etkilemektedir.

H1: Yapısal personel güçlendirme rekabet zekâsı kapsamını (a-farkındalık, b- rekabet kültürü cörgütsel katılım) olumlu olarak etkiler.

$\mathbf{H}_{2}$ : Yapısal personel güçlendirme rekabet zekâsı sürecini (a- odaklanma, b- bilgi tasarımı, ckıyaslama) olumlu olarak etkiler.

H3: Psikolojik personel güçlendirme rekabet zekâsı kapsamını (a-farkındalık, b- rekabet kültürü c- örgütsel katılım) olumlu olarak etkiler.

H4: Psikolojik personel güçlendirme rekabet zekâsı sürecini (a- odaklanma, b- bilgi tasarımı, ckıyaslama) olumlu olarak etkiler.

Araştırmadaki değişkenler arasındaki ilişkiyi özetleyen Model Şekil 1'de verilmiştir.

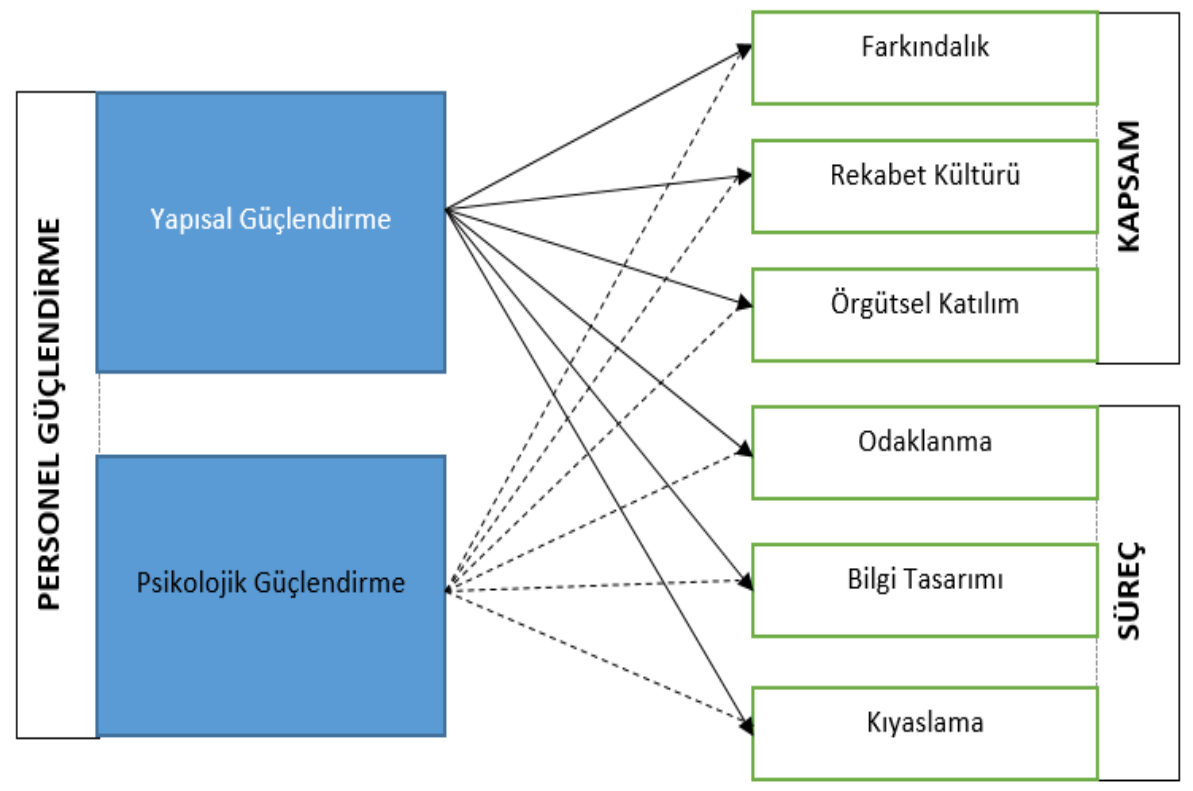

Şekil 1: Araştırmanın Modeli

\section{YÖNTEM}

Bu kısımda örneklem ve ölçeğin geliştirmesine ilişkin bilgilere yer verilecektir.

\section{Evren ve Örneklem}

Akdeniz Bölgesinde bulunan ve Türkiye'nin en önemli turizm merkezlerinden biri olan Antalya'da faaliyet gösteren 4 ve 5 yıldızlı oteller araştırmanın evrenini oluşturmaktadır. Araştırmada için basit tesadüfi örnekleme yöntemi kullanılarak işgörenlerle yüz yüze görüşme yapılmış ve verilerin kimseyle paylaşılmayacağı, sadece bilimsel amaçlar için kullanılacağı 
belirtilmiştir. 2019 yılı yaz döneminde otel çalışanlarına 430 adet anket uygulanmış olup eksik bilgisi olanlar çıkarıldıktan sonra 400 anket analize tabi tutulmuştur.

\section{Araştırma Ölçeğinin Geliştirilmesi}

Araştırmada kullanılan ölçekler uluslararası kabul görmüş çalışmalardan elde edilmiş ve detayları aşağıda verilmiştir.

Personel Güçlendirme: Yapısal personel güçlendirme düzeyini ölçmek amacıyla araştırmada yer alan ve 9 ifadeden oluşan ölçek, Cacioppe'nin (2006) oteller üzerinde yaptığ 25 soruluk çalışmadan alınmıştır. Ölçeğin 5 soruluk versiyonunu Yıldırım ve Karabey 2016 yılında Türkiye' de oteller üzerinde uygulamış ve yüksek güvenirlik elde etmiştir.

Psikolojik personel güçlendirme Spreitzer'in (1995) 12 soruluk çalışmasından alınmış ve araştırmamızda 11 soru ile tek boyut olarak değerlendirilmiştir. Ölçek Türkiye'de birçok araştırmacı tarafından kullanılmış ve güvenirlik sağlamıştır (Kerse, 2013: 72; Yıldırım ve Naktiyok, 2017). Ölçekler 5' li Likert tipindedir (1: kesinlikle katılmıyorum- 5: kesinlikle katıliyorum).

Rekabet Zekâsı: Rekabet zekâsı ölçeğini Kula 2019 yılında Day ve Wensley (1988), Dickson (1992), Sawka ve diğerleri (1996), Hamel ve Parahalad (1996), Li ve Calantone (1998), Prescott (1999), Guimaraes (2000), Teo ve Choo (2001), Qiu (2008), Saayman vd. (2008), Dishman ve Calof (2008), Wright vd., (2013), Köseoğlu vd., (2016), Hall ve Bensoussan'nın (2007) akademik kitabı ile Dugal (1996), Hesford (1998), Grooms (2001), Chen'in (2012) çalışmalarından yararlanılarak geliştirmiştir. Kula (2019) araştırmasında rekabet zekâsını kapsam ve süreç olarak ele almış, 28 soruyu toplam 7 alt boyutta değerlendirmiştir. Bu araştırmada da farkındalık 2, rekabet kültürü 6, örgütsel katılım 7, odaklanma 2, bilgi tasarımı 4 ve kıyaslama 3 soru ile toplam 24 soru 7 alt boyut olarak değerlendirilmiştir. Ölçekler 5 ' li Likert tipindedir (1: kesinlikle katılmıyorum- 5: kesinlikle katıliyorum).

Ölçekler için güvenilirlik analizi yapılmış olup Cronbach alfa değerleri rekabet zekâsı için 0,88 , personel güçlendirme için 0,95 bulunmuştur. Bir ölçeğin güvenilir kabul edilmesi için Cronbach değerinin 0,70 veya daha yüksek olması gerekir (Naktiyok, 2004: 243-244). Bu nedenle araştırmada kullanılan ölçeklerin oldukça güvenilir olduğu tespit edilmiştir.

Kullanılan ölçeklerin yapı geçerliliğini ortaya koymak amacıyla hem açıklayıcı hem de doğrulayıcı faktör analizi yapılmıştır. Açıklayıcı faktör analizi sonuçları doğrulanınca doğrulayıcı faktör analizi de yapılmıştır. Doğrulayıcı faktör analizi sonuçları aşağıda ilgili tablolarda verilmiştir. Sonuç olarak tüm ölçeklerin yüksek düzeyde geçerlilik sergilemiştir. Ayrıca LISREL programının modifikasyon yönlendirmesi gereği ölçeklerde her biri için 5'i geçmemek üzere bazı ifadeler birbirine bağlanmıştır ve dört soru çıkarılmıştır. Bu durum ile ilgili bilgi ilgili şeklin altında gösterilmiştir.

Yukarıda ölçüm metotları ortaya konulan bağımlı ve bağımsız değişkenlere ek olarak bu araştırmada katılımcı profilinin daha iyi yorumlanabilmesi için cinsiyet, yaş, medeni durum, eğitim düzeyi, çalışma süresi ve yönetsel görev gibi demografik değişkenler Tablo 1'de verilmiştir.

\section{ANALIZZ ve BULGULAR}

Tablo 1'de araştırmaya katılan çalışanlarla ilgili demografik bilgiler verilmiştir. 
Tablo 1: Katılımcılara İlişkin Demografik Veriler

\begin{tabular}{|c|c|c|c|}
\hline Değişken & Kategori & Frekans & Yüzde \\
\hline \multirow{2}{*}{ Cinsiyet } & Kadın & 192 & 48 \\
\hline & Erkek & 208 & 52 \\
\hline \multirow{4}{*}{ Yaş } & 20 ve alt1 & 35 & 8,75 \\
\hline & $21-30$ & 128 & 32 \\
\hline & \begin{tabular}{|l|}
$31-40$ \\
\end{tabular} & 135 & 33,75 \\
\hline & 41 ve üzeri & 102 & 25,5 \\
\hline \multirow[t]{5}{*}{ Medeni Durum } & Evli & 183 & 45,75 \\
\hline & Bekar & 217 & 54,25 \\
\hline & Önlisans ve altı & 159 & 39,75 \\
\hline & \begin{tabular}{|l|} 
Lisans \\
\end{tabular} & 203 & 50,75 \\
\hline & Y.Lisans/Doktora & 38 & 9,5 \\
\hline \multirow{4}{*}{ Çalışma Süresi } & 1 yıldan az & 46 & 11,5 \\
\hline & $1-2$ yil & 56 & 14 \\
\hline & 3-4 y1l & 133 & 33,25 \\
\hline & 5 yıl ve üzeri & 165 & 41,25 \\
\hline \multirow{2}{*}{$\begin{array}{l}\text { Yöneticilik Görevi } \\
\text { Var mı? }\end{array}$} & Evet & 176 & 44 \\
\hline & Hayır & 224 & 56 \\
\hline \multicolumn{2}{|r|}{ TOPLAM } & 400 & 100 \\
\hline
\end{tabular}

Tablo 1'e göre araştırmaya katılanların \% 48'i kadın ve \% 52'si erkektir. Araştırmaya katılanların $\%$ 8,75'i 20 yaşın altında, \% 32'si 21-30 yaş aralığında, \% 33,75'i 31-40 yaş aralığında ve \% 25,5'i 41 yaşın üzerindedir. katılımcıların \% 45,75'i evliyken \% 54,25'i bekârdır. Katılımcıların, \% 39,75'i önlisans veya altı, \% 50,75'i lisans ve \% 9,5'i lisansüstü mezunudur. Katılımclların \% 11,5'i 1 yıldan az süredir, \% 14'ü 1-2 yıl arası, \% 33,25'i 3-4 yıl arası ve \% 41,25'i 5 yıl ve üzeri süredir bu otelde çalışmaktadır. Son olarak katılımcıların \% 44'ünün yöneticilik görevi varken, \% 56'sının yöneticilik görevi bulunmamaktadır. Doğrulayıcı faktör analizlerinin sonuçları ve uyum indeksleri kabul değerleri sırasıyla Tablo 2 ve Tablo 3'te gösterilmiştir:

Tablo 2: Doğrulayıcı Faktör Analizleri Sonucunda Elde Edilen Uyum İyiliği İndeksleri

\section{Değişken}

\begin{tabular}{lcccccccc} 
& $\chi^{2}$ & $\mathbf{( s d )}$ & $\chi^{2} / \mathbf{s d}$ & $\mathbf{C F I}$ & NFI & NNFI & AGFI & RMSEA \\
Personel & 585,32 & 164 & 3,56 & 0,98 & 0,97 & 0,98 & 0,85 & 0,080 \\
Güçlendirme & & & & & & & & \\
Rekabet Zekâs1 & 805,84 & 231 & 3,48 & 0,95 & 0,93 & 0,94 & 0,84 & 0,079 \\
\hline
\end{tabular}

Tablo 3: Uyum İndeksleri Kabul Değerleri

\begin{tabular}{|c|c|c|}
\hline $\begin{array}{c}\text { Uyum İyiliği } \\
\text { Ölçüsü }\end{array}$ & İyi Uyum Değerleri & Kabul Edilebilir Uyum Değerleri \\
\hline$\chi^{2} / \mathrm{df}$ & $\chi^{2} / \mathrm{df} \leq 2$ & $\chi^{2} / \mathrm{df} \leq 5$ \\
\hline $\mathrm{RMSEA}$ & $0.00 \leq \mathrm{RMSEA} \leq 0.05$ & $0.05 \leq \mathrm{RMSEA} \leq 0.10$ \\
\hline $\mathrm{AGFI}$ & $0.90 \leq \mathrm{AGFI} \leq 1.00$ & $0.80 \leq \mathrm{AGFI} \leq 0.90$ \\
\hline $\mathrm{CFI}$ & $0.95 \leq \mathrm{CFI} \leq 1.00$ & $0.90 \leq \mathrm{CFI} \leq 0.95$ \\
\hline $\mathrm{NFI}$ & $0.95 \leq \mathrm{NFI} \leq 1.00$ & $0.90 \leq \mathrm{NFI} \leq 0.95$ \\
$\mathrm{NNFI}$ & $0.95 \leq \mathrm{NNFI} \leq 1.00$ & $0.90 \leq \mathrm{NNFI} \leq 0.95$ \\
\hline
\end{tabular}

Kaynak: Schermelleh-Engel ve Moosbrugger, 2003; Şimşek, 2007; Akbaba,2019 
Tablo 2 ve 3'e göre araştırmada yer alan değişkenlerin doğrulayıcı faktör analizi sonucunda genel olarak iyi uyum sergilediği görülmüştür. Şekil 2 ve 3' de standardize faktör yükleri verilmiştir.

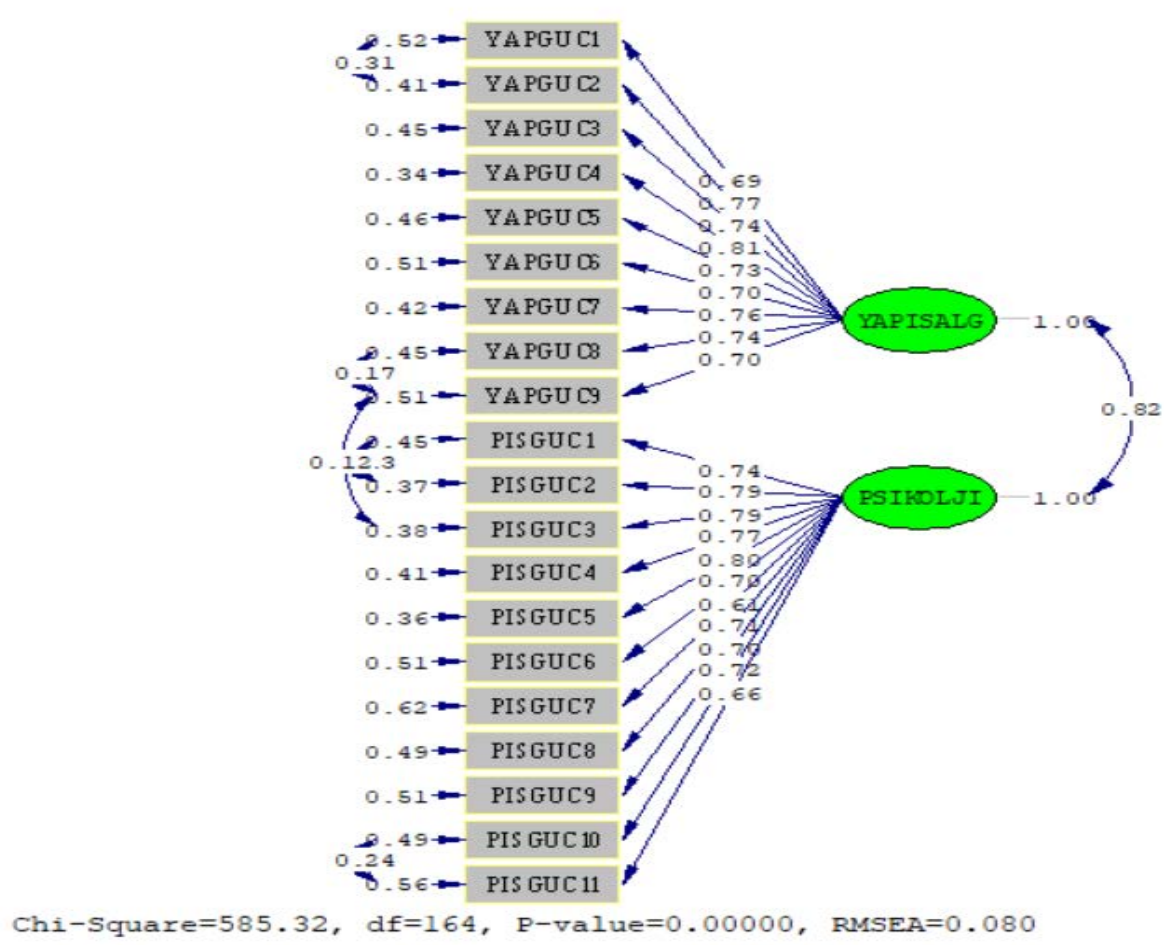

Şekil 2: Personel Güçlendirmeye İlişkin Standardize Yüklere Ait LISREL Çıtısı

Şekil 2'ye göre personel güçlendirmeye ilişkin tasarlanan ölçekten hiçbir ifade ölçekten çıkarılmamıştır. Tüm ifadelerin standardize yükleri 0,50'nin üzerinde ve 1'in altındadır. LISREL programının yönlendirmesi gereği YAPGUC1-YAPGUC2, YAPGUC8-YAPGUC9, YAPGU9PISGUC3, PISGUC1-PISGUC2 ve PISGUC10-PISGUC11 olmak üzere 5 ifade bağlanmıştır. Yapısal güçlendirme soruları YAPGUC, personel güçlendirme soruları PISGUC olarak kısaltılmıştır.

Şekil 3'e göre rekabet zekâsına ilişkin LISREL programını yönlendirmesi gereği tasarlanan ölçekten örgütsel katılımdan 1 ifade, odaklanmadan 1 ifade, kıyaslamadan 1 ifade tasarımdan 1 ifade ölçekten çıkarılmıştır. Tüm ifadelerin standardize yükleri $0,40^{\prime}$ in üzerinde ve 1'in altındadır. LISREL programının yönlendirmesi gereği FARK2-KULTUR1, FARK2-KULTUR2, FARK2-KULTUR3, KULTUR5-KULTUR6 ve KATIL6-KATIL7 olmak üzere 5 ifade bağlanmıştır. Sorularda farkındalık FARK, rekabet kültürü KULTUR, örgütsel katılım KATIL, odaklanma ODAK, bilgi tasarımı BILTAS ve kıyaslama KIYAS olarak kısaltılmıştır. Alt boyutlar ise FARK, REKKULT, ORKATIL, ODAK, BILTAS, KIYAS olarak kısaltılmıştır. 


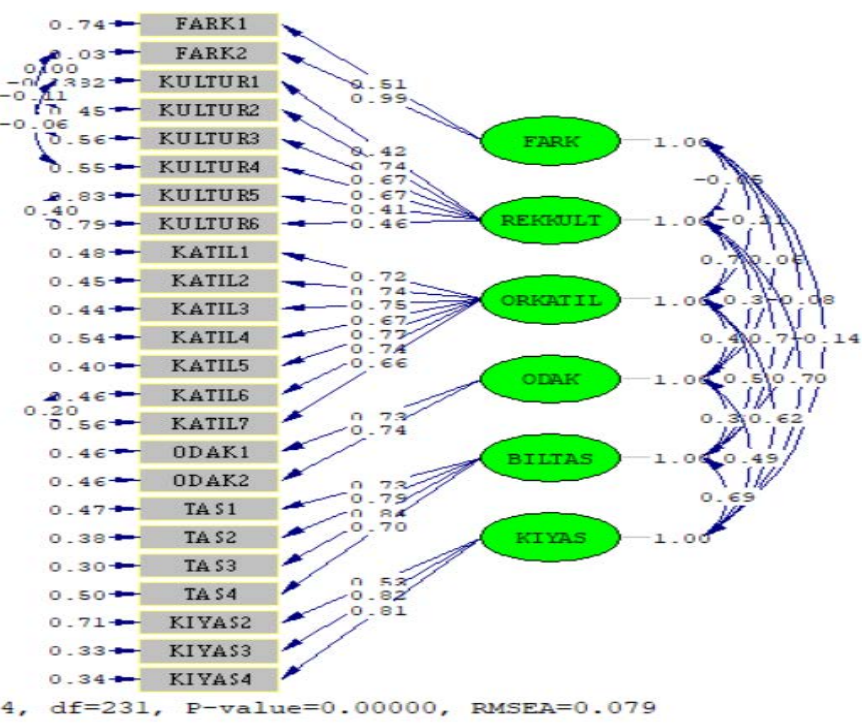

Şekil 3: Rekabet Zekâsına İlişkin Standardize Yüklere Ait LISREL Çıktısı

Araştırma modelindeki değişkenlerin yapısal özellikleri doğrulandıktan sonra, yol analiziyle bir bütün olarak modelin ve hipotezlerin doğrulanıp doğrulanmadığı test edilmektedir. Başlıca uyum iyiliği değerlerini ve regresyon katsayılarını gösteren yol analizi sonuçları Şekil 4'te verilmiştir:

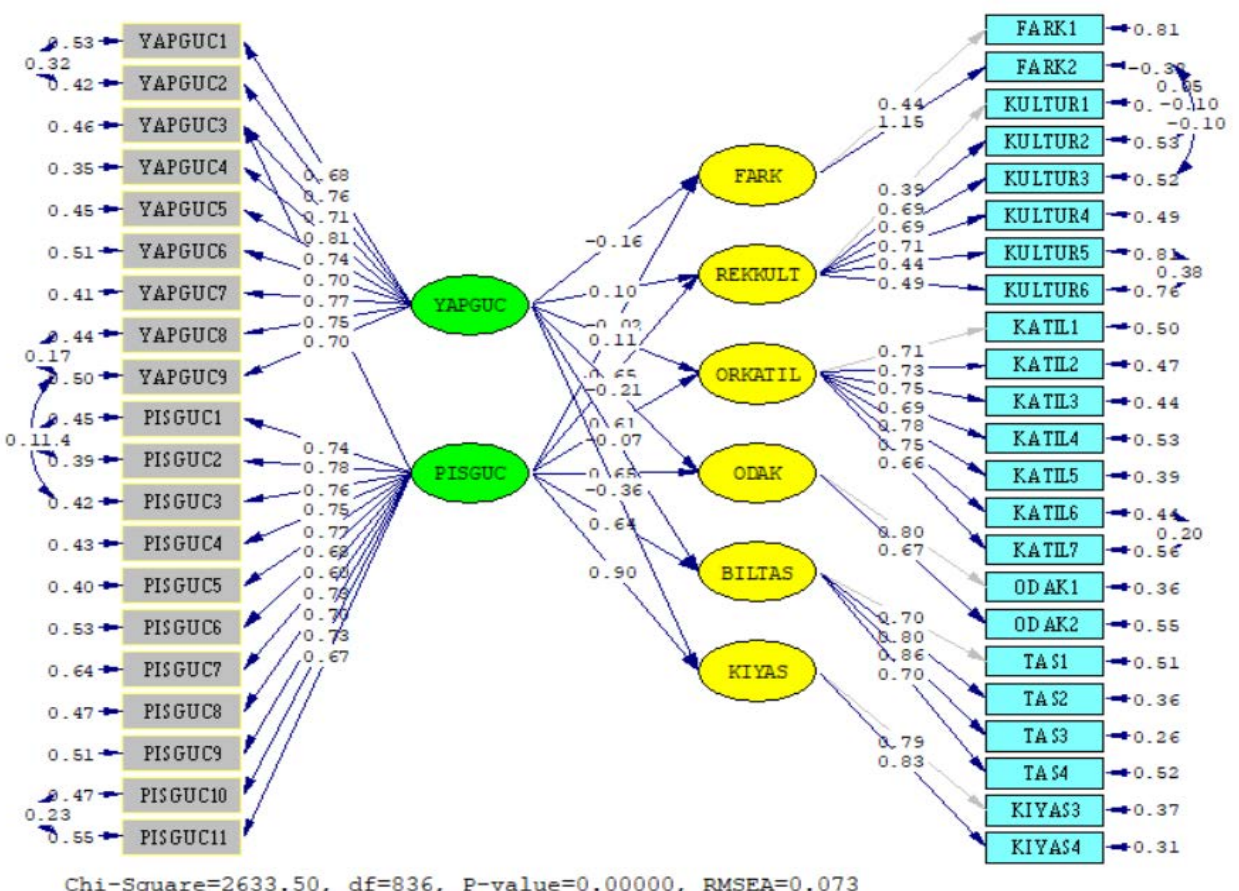

Şekil 4: Araştırma Modeline İlişkin Yol Analizi Standardize Değerler 
Şekil 4' e göre DFA'daki tüm ifade bağlamaları Yapısal Eşitlik Modelinde aynen uygulanmıştır. Standardize yüklerin 0,40' in üstünde 1'in altında olduğu gözükmektedir. Yapısal güçlendirme rekabet kültürünü, örgütsel katılımı, bilgi tasarımını anlamlı ve olumlu olarak etkilerken, farkındalık, odaklanma ve kıyaslamayı anlamlı olarak etkilememiştir. Diğer yandan psikolojik güçlendirme farkındalık, rekabet kültürü, örgütsel katılım, odaklanma, bilgi tasarımı ve kıyaslamayı anlamlı ve olumlu olarak etkilemiştir. Yapısal Eşitlik Modelinin kabulüne ilişkin uyum indeksi sonuçları aşağıda verilmiştir.

Tablo 4: Yapısal Eşitlik Modellemesi Analizleri Sonucunda Elde Edilen Uyum İyiliği İndeksleri

\begin{tabular}{ccccccccc}
\hline Değişken & & & \multicolumn{7}{c}{ Değerler } \\
& $\chi^{2}$ & (sd) & $\chi^{2 / \text { sd }}$ & CFI & NFI & NNFI & AGFI & RMSEA \\
$\begin{array}{c}\text { Araştırma YEM } \\
\text { Değerleri }\end{array}$ & 2633,50 & 836 & 3,15 & 0,96 & 0,95 & 0,96 & 0,80 & 0,073 \\
\hline
\end{tabular}

Tablo 4'te yazılan YEM uyum indekslerine göre model kabul edilmektedir.

Tablo 5: Hipotez Testi Sonuçları

\begin{tabular}{|c|c|c|}
\hline Yol & Hipotez & Sonuç \\
\hline Yapısal Güçlendirme & $\mathrm{H}_{1 \mathrm{a}}$ & Reddedildi \\
\hline Yapısal Güçlendirme & $\mathrm{H}_{1 \mathrm{~b}}$ & Kabul edildi \\
\hline Yapısal Güçlendirme & $\mathrm{H}_{1 \mathrm{c}}$ & Kabul edildi \\
\hline Yapısal Güçlendirme & $\mathrm{H}_{2 \mathrm{a}}$ & Reddedildi \\
\hline Yapısal Güçlendirme & $\mathrm{H}_{2 b}$ & Kabul edildi \\
\hline Yapısal Güçlendirme & $\mathrm{H}_{2 \mathrm{c}}$ & Reddedildi \\
\hline Psikolojik Güçlendirme $\rightarrow$ Farkındalık & $\mathrm{H}_{3 \mathrm{a}}$ & Kabul edildi \\
\hline Psikolojik Güçlendirme $\rightarrow$ Rekabet Kültürü & $\mathrm{H}_{3 b}$ & Kabul edildi \\
\hline Psikolojik Güçlendirme_Örgütsel Katılım & $\mathrm{H}_{3 c}$ & Kabul edildi \\
\hline Psikolojik Güçlendirme__Odaklanma & $\mathrm{H}_{4 a}$ & Kabul edildi \\
\hline Psikolojik Güçlendirme_Bilgi Tasarımı & $\mathrm{H}_{4 b}$ & Kabul edildi \\
\hline Psikolojik Güçlendirme Kıyaslama & $\mathrm{H}_{4 \mathrm{c}}$ & Kabul edildi \\
\hline
\end{tabular}

Tablo 5'te hipotezlerin desteklenip desteklenmediği gösterilmiştir. T değerlerine göre $\mathrm{H}_{1 a}, \mathrm{H}_{2 a}$ ve $\mathrm{H}_{2 c}$ hipotezleri reddedilmiş diğer hipotezler kabul edilmiştir. Araştırmaya ait bulgular sonuç kısmında tartışılmıştır.

\section{SONUÇ ve TARTIŞMA}

Personel güçlendirmenin rekabet zekâsına olan etkisini ölçmek amacıyla 400 katılımcı üzerinde gerçekleştirilen araştırmanın sonuçlarına göre yapısal güçlendirmenin ortalaması 3,81, psikolojik güçlendirmenin ortalaması 3,91, rekabet zekâsı sürecinin ortalaması 3,66 ve rekabet zekâsı kapsamının ortalaması 3,69 olarak tespit edilmiştir. Toplam personel güçlendirme ortalaması 3,86 ve toplam rekabet zekâsı ortalaması 3,68'dir. Bu durum araştırmaya katılan otellerde personel güçlendirmenin ve rekabet zekâsının düşük olmadığını göstermektedir. Araştırmanın 4 ve 5 yıldızlı otellerde yapıldığı düşünüldügüünde belirli bir kurumsallık düzeyine ulaşmış bu işletmelerde böyle bir sonucun çıkması beklenmektedir. Buna rağmen yapılacak doğru uygulamalarla ortalamaların daha yükseltilebileceğine de dikkat çekmek gerekmektedir.

Yapısal güçlendirme rekabet kültürü, örgütsel katılım ve bilgi tasarımını anlamlı ve olumlu olarak etkilemiştir. Daha açlk bir ifade ile işletmelerin yapısal personel güçlendirme düzeyi 
yükseldikçe rekabet kültürü, örgütsel katılım ve bilgi tasarımı da yükselmektedir. Buna karşın yapısal güçlendirme farkındalık, odaklanma ve kıyaslamayı anlamlı olarak etkilememiştir. Bu durum ise farkındalık, odaklanma ve kıyaslama faaliyetlerinin daha çok soyut ve teorik bir durum olması ile ilişkili olabilir. Yapısal güçlendirme genellikle pratiğe yönelik bir uygulamadır ve rekabet zekâsı ile ilgili olumlu sonuçları rekabet kültürü, kararlara katılım ve bilgi tasarımı gibi daha çok uygulamaya yönelik somut kısımlarda görülmüştür.

Yapısal güçlendirmenin bilgi tasarımını artırdığı sonucundan hareketle Hannon'un (1997) kaynak temelli bakış açısı örnek gösterilebilir. Buna göre işletmelerde anahtar başarı faktörlerinin tanımlanmasının ve geliştirilmesinin, işletmelerin insan kaynakları sermayesi ve sahip olduğu teknoloji gibi benzersiz özelliklerine katkı sunarak öğrenme düzeylerini dolayısıyla rekabet zekâ düzeylerini artıracağı ifade edilmiştir (Ghemawat, 1986; Barney, 1991). Diğer yandan yapısal güçlendirmenin örgütsel katılımı artırdığı sonucunu destekleyen çalışmalar da bulunmaktadır. Güçlendirme, çalışanların hem kişisel gelişime hem de sürdürülebilir örgütsel gelişime yönlenmelerini teşvik etmektedir. Özellikle personel güçlendirme sayesinde eğitilen ve gelişen çalışanın, doğru kararlar alarak işletmenin rekabet üstünlüğü sağlama çabalarına katkı sunduğu tespit edilmiştir (Senge, 1990; Frey, 1993; Garvin, 1993). Bu nedenle işletmelere rekabet zekâlarını yükseltebilmek için takım çalışmasını esas alan, çalışanların deneyim kazanma imkânına sahip olduğu, bilgilerin paylaşıldığı veya erişilebildiği ve çalışanlara örgütsel destek verildiği yapısal güçlendirme araçlarının kullanılması önerilmektedir.

Psikolojik güçlendirme ise farkındalık, rekabet kültürü, örgütsel katılım, odaklanma, bilgi tasarımı ve kıyaslama olmak üzere rekabet zekâsının tüm alt boyutlarını anlamlı ve olumlu olarak etkilemiştir. İran'da Kahreh ve diğerleri (2011), Hindistan'da Ghosh (2013), Irak'ta Kadhima ve diğerleri (2018) personel güçlendirmenin bilgi yönetim kapasiteleriyle rekabet avantajı sağladığını ortaya koymuşlardır. Diğer yandan Amerika Birleşik Devletleri'nde WalMart, VISA ve Trader Joe's gibi birçok şirkette personel güçlendirme uygulaması bulunmaktadır. Yapılan araştırmalara göre perakende gıda endüstrisindeki bir şirket olan Trader Joe's, daha fazla güçlendirme ile yıllık satış büyümesini \% 15'den \% 26'ya çıkarmıştır. Mağaza başına satışlar yılda \% 10 artarken, mağaza sayısı neredeyse \% 100 artmıştır (Randolph ve Sashkin, 2002). Psikolojik güçlendirme örgüt üyelerine yeterlilik, özerklik, özgüven ve motivasyon kazandırarak örgütsel verimliliğin artmasına yardımcı olur. Özgüven kazanan ve motive olmuş çalışan bilgiyi elde etmek için daha fazla çaba gösterecektir. Cook ve diğerlerine göre (1997) güçlendirilmiş personel enerjisini üstlendiği göreve harcayacağından aktif bir sorun çözücü olacaktır. Bu durum güçlendirilmiş personele bir esneklik kazandırır ve kilit noktalarda alternatif yolları denemesini sağlayarak verimliliği artırır. Özellikle turizm işletmeleri gibi hizmet üreten işletmelerde işgörenler müşterilerin ihtiyaçlarını doğrudan karşılamaktadır. Bowen ve Lawler, (1992) yaptığ1 araştırmada hizmetin sunumu esnasında müşteri ihtiyaçlarına hızlı cevap verebilme ve müşteri memnuniyetsizliğinin yaşandığı durumlarda alınan şikâyetlere hızlı geri dönüş yapabilmenin personel güçlendirme ile sağlandığını ifade etmiştir. Güçlendirilmiş çalışanlar işlerin sorumluluğunu bizzat kendileri üstleneceği ve paylaşılan bilgiyi rahatlıkla elde edebileceği için işler daha yüksek kalitede tamamlanacaktır (Sharafat, 1997; Baltaş, 2001; Yıldırım ve Karabey, 2016). Tüm bu bilgiler araştırmadan elde edilen bir sonuç olan psikolojik güçlendirmenin rekabet zekâsı düzeyini artırmasının temellerini yansıtmaktadır. Bu nedenle turizm işletmelerine sürdürülebilir rekabet üstünlügü sağlayan rekabet zekâsına sahip işletmeler oluşturulabilmek için personel güçlendirme uygulamaları önerilmektedir. Araştırmadan elde edilen sonuçlara göre rekabet zekâsı düzeyini yükseltebilmek için genel olarak işletmelere ve politika belirleyicilere aşağıdaki öneriler sunulabilir. Bunlar;

- Sorumluluğu ve riski bölebilecek çalışma takımları oluşturmak,

- Çalışanların kararlara katılımını sağlamak, 
- Bilginin rahatça paylaşıldığı güven ortamı oluşturmak,

- Bilginin güvenirliğini analiz edebilmek ve kararları doğru verebilmek için çalışanlara düzenli olarak eğitim vermek,

- Örgüt içerisinde ortak bir vizyon paylaşmak,

- Üyelere özgüven ve motivasyon kazandırmak şeklinde sıralanabilir.

$\mathrm{Bu}$ araştırma zaman ve maliyet kısıtları nedeniyle tek bir bölgede turizm sektöründe yapılmıştır. Dolayısıyla gelecek araştırmalara personel güçlendirme ve rekabet zekâsı ilişkisinin başka endüstrilerde uygulanması önerilmektedir. Ayrıca rekabet zekâsı kavramı Türkiye'deki işletmelerde oldukça az araştırılmış bir kavramdır. Hem işletmelerin genel olarak rekabet zekâsı düzeylerini tespit etmek hem de örgüt kültürü, örgütsel iklim ve örgüt içi politika gibi diğer örgütsel davranış değişkenlerinden nasıl etkilendiğini ortaya koymak gelecek araştırmalara önerilmektedir. Bu araştırmada tek bir seferde anket üzerinden veri toplanmıştır ve elde edilen bilgiler katılımcıların cevaplarıyla sınırlıdır. Gelecek araştırmalara örgütsel uygulamalardan veri sağlanarak işletmelerin rekabet zekâsı düzeylerini tespit etmeleri önerilmektedir.

\section{KAYNAKÇA}

Akbaba, A. İ. (2019). Endüstri 4.0 ve 3 Boyutlu Yazıcılar. (1. Basım), Ankara: İmaj Yayınevi.

Baltaş, A. (2001). Ekip Çalısması ve Liderlik. (2.Basım), İstanbul: Remzi Kitabevi.

Barney, J. (1991). Firm resources and sustained competitive advantage. Journal of Management, 17(1), 99-120.

Block, P. (1987). The Empowerment Manager: Positive Political Skills at Work. San Francisco CA: Jossey-Bass.

Boone, L. E. and Kurtz D. L. (2013). Contemporary Business. (14. Edition), (Çeviren, Yalçın A.), Ankara: Nobel Yayın.

Bowen, D. E. and Lawler E. E. (1992). The empowerment of service workers: what, why, how and when. Sloan Management Review, 20(4), 33-35.

Cacioppe, R. (1998). Structured empowerment: An awar-winning program at the Burswood Resort Hotel. Leadership \& Organizational Development Journal, 19(5), 264-274.

Chen, X. (2012). Impact of business intelligence and its infrastructure flexibility on competitive advantage: an organizational agility perspective, Doctoral Thesis, University of Nebraska, Lincoln.

Conger, J. A. and Kanungo, R. N. (1988). The Empowerment Process: Integrating Theory and Practice. The Academy of Management Review, 13(3), 478-490.

Cook, C. W., Hunsaker, P. L. and Coffey, R. E. (1997). Management and Organizational Behavior. (Second Edition), Irwin McGraw-Hill.

Day, G. S. and Wensley, R. (1988). Assessing advantage: a framework for diagnosing competitive superiority. Journal of Marketing, 52(2), 1-20.

DeCarlo, D. (2004). Extreme project management. (1st Edition), San Francisco CA: The Jossey Bass.

Dickson, P. R. (1992). Toward a general theory of competitive rationality. Journal of Marketing, 56(1), 69-83. 
Dishman, P. L. and Calof, J. L. (2008). Competitive intelligence: a multiphasic precedent to marketing strategy. European Journal of Marketing, 42(7/8), 766-785.

Du Toit, A.S.A. (2015). Competitive intelligence research: an investigation of trends in the literatüre. Journal of Intelligence Studies in Business, 5 (2), 14-21.

Dugal, M. S. (1996). Integrating competitive intelligence in organizations. Doctoral Thesis, University of Pittsburgh, Pittsburgh.

Dutka, A. F. (1999). Competitive intelligence for the competitive edge. New York: McGraw-Hill/Irwin.

Emet, C. (2006). Personelin Güçlendirilme Alg̨ları İle Örgütsel Kültür Arasındaki İlişkinin Bankacıllk Sektöründe Ampirik Olarak İncelenmesi. Yayımlanmamış Yüksek Lisans Tezi, Dumlupınar Üniversitesi, Kütahya.

Erstad, M. (1997). Empowerment and organizational change. International Journal of Contemporary Hospitality Management, 9(7), 325-333.

Fleisher, C. S. (2008). Using open source data in developing competitive and marketing intelligence. European Journal of Marketing, 42(7/8), 852-866.

Frey, R. (1993). Empowerment or else. Harvard Business Review, 3, 80-94.

Gabriel, J.M.O. and Adiele, K.C. (2012). Competitive intelligence as panacea for environmental vagaries in Nigeria. Economic Journal of A 2 Z, 1(1), 25-30.

Garvin, D.A. (1993). Building a learning organization. Harvard Business Review, 4, 78-91.

Gelb, B. D., Saxton, M. J., Zinkhan, G. M. and Albers, N. D. (1991). Competitive intelligence: insights from executives. Business Horizon, 34(1), 43-47.

Ghemawat, P. (1986). Sustainable advantage. Harvard Business Review, 5, 53-58.

Ghosh, A. K. (2013). Employee empowerment: a strategic tool to obtain sustainable competitive advantage. International Journal of Management, 30(3), 95.

Grooms, T. F. (2001). Marketing intelligence: executive management perceptions of value. Doctoral Thesis, Brunel University, London.

Guimaraes, T. (2000). The impact of competitive intelligence and IS support in changing small business organizations, Logistics Information Management, 13(3), 117125.

Guo, L., Li T., and Zhang. H. (2014). Strategic information sharing in competing channels. Prod. Operation Management, 23(10), 1719-1731.

Hall, C. and Bensoussan, B. E. (2007). Staying ahead of the competition: how firms really manage their competitive intelligence and knowledge; evidence from a decade of rapid change. Singapur: World Scientific Publishing.

Hamel, G. and Prahalad, C. K. (1996). Competing for the future. Boston: Harvard Business Press.

Hannon, J. M. (1997). Leveraging hrm to enrich competitive intelligence. Human Resource Management, 36 (4), 409-422.

Hesford, J. W. (1998). Determinants of the use of competitors' accounting information by competitive intelligence professionals, Doctoral Thesis, University of Southern California, California.

Hunt, S. D. and Morgan, R. M. (1995). The comparative advantage theory of competition. Journal of Marketing, 59 (2), 1-15. 
Jaworski, B. J., Macinnis, D. J. and Kohli, A. K. (2002). Generating competitive intelligence in organizations. Journal of Marketing Focused Management, 5(4), 279-307.

Kadhima, R. I., Mhsen, A. M. and Hameedah, G. G. (2018). Empowerment as a strategy to achieve the competitive advantage of organizations: a mediating role of organizational learning, Management Science Letters, 8, 903-912.

Kahreh, M. S., Ahmadi, H. and Hashemi, A. (2011). Achieving competitive advantage through empowering employees: An empirical study. Far East Journal of Psychology and Business, 3(2), 2637.

Keiser, B. E. (1987). Practical competitor intelligence. Planning Review, 15(5), 14-45.

Kerse, G. (2013). Personel güçlendirme ile bireyin yaratıcllı algısı arasındaki ilişki: bankacıllk sektöründe bir uygulama. Yayınlanmamış Doktora Tezi, Atatürk Üniversitesi, Erzurum.

Koçel, T. (2011). İşletme Yöneticiliği. (13. Basım), İstanbul: Beta Basım.

Kotler, P. and Keller K. L. (2003). Marketing management. (International Edition), Printice Hall, Upper Saddle River, NJ.

Köseoglu, M. A., Ross, G. and Okumus, F. (2016). Competitive intelligence practices in hotels. International Journal of Hospitality Management, 53, 161-172.

Kula, M.E. (2019). Stratejik düşünce ve rekabet zekâsı otomotiv ve iletişim endüstrilerinde karşılaştırmalı bir araştırma. Yayınlanmamış Doktora Tezi, Atatürk Üniversitesi, Erzurum.

Kumar, V., Saboo, A. R., Agarwal, A. and Kumar, B. (2020). Generating competitive intelligence with limited information: a case of the multimedia industry. Production and Operations Management, 29(1), 192-213.

Li, I.C., Chen, Y.C. and Kuo, H.T. (2008). The Relationship between work empowerment and work stress perceived by nurses at long-term care facilities in Taipei City, Journal of Clinical Nursing, 17, 3050-3058.

Li, T. and Calantone, R. J. (1998). The impact of market knowledge competence on new product advantage: conceptualization and empirical examination, Journal of Marketing, 62(4), 13-29.

Manyika, J., Chui, M., Brown, B., Bughin, J., Dobbs, R., Roxburgh, C. and Byers, A. H. (2011). Big data: the next frontier for innovation, competition, and productivity. [Online]. http://www.mckinsey.com/insights/mgi/research/technology_and_innovation/big_data_the_ne xt_frontier_f or_innovation [Erişim Tarihi: 25.12.2019].

Margulles, J. S. and Kleiner, B. H. (1995). Nevv designs of work groups: applications of empowerment. Empovverment in Organizations, 3(2), 12-18.

Miller, J. (2000). Millennium intelligence: understanding and conducting competitive intelligence in the digital age. New Jersey: Cyber Age Books.

Murphy, C. (2005). Competitive intelligence: gathering, analysing and putting it to work. Gower House: Gower Publishing Limited.

Naktiyok, A. (2004). İ̧̧ girişimcilik. (1. Basım), İstanbul: Beta Yayınları.

Özgen, H. ve Türk, M. (1997). Hizmet sektöründe rekabette başarının anahtarı: personel güçlendirme (empowerment). Todaie Amme İdaresi Dergisi, 30 (4), 80-96.

Pellissier, R. and Nenzhelele, T.E. (2013). Towards a universal definition of competitive intelligence. South African Journal of Information Management, 15(2), 1-7. 
Prescott, J. E. (1999). The evolution of competitive intelligence. International Review of Strategic Management, 6, 37-52.

Qiu, T. (2008). Scanning for competitive intelligence: a managerial perspective, European Journal of Marketing, 42 (7/8), 814-835.

Randolph, W. A. and Sashkin, M. (2002). Can organizational empowerment work in multinational settings? The Academy of Management Executive, 16(1), 102-115.

Ripley, R.E. and Ripley, M.J. (1992). Empowerment, the cornerstone of quality: empowering management in innovative organizations in 1990's, Management Decision, 30(4), 20-43.

Saayman, A., Pienaar, J., De Pelsmacker, P., Viviers, W., Cuyvers, L., Muller, M. L. and Jegers, M. (2008). Competitive intelligence: construct exploration, validation and equivalence. In Aslib Proceedings, Emerald Group Publishing Limited, 60(4), 383-411.

Sawka, K. A., Francis, D. B. and Herring, J. P. (1996). Evaluating business intelligence systems: how does your company rate?, Competitive Intelligence Review, 6(4), 22-25.

Schermelleh E. K., Moosbrugger, H. and Müller, H. (2003). Evaluating the fit of structural equation models: tests of significance and descriptive goodness-of-fit measures, Methods of Psychological Research Online, 8(2), 23-74.

Senge, P. (1990). The fifth discipline. New York: Doubleday.

Sharafat, K. (1997). The key to being a leader company: empowerment, Journal for Quality and Participation, 21 (1), 46.

Sigler T. H. and Pearson C. M. (2000). Creating an empowering culture: Examing the relationship between organizational culture and perceptions of empowerment. Journal of Quality Management, $5,27-52$.

Solberg Søilen, K. (2010). Boosting innovation and knowledge through delocalization: market intelligence at trade shows. Problems and Perspectives in Management, 8(3), 200-207.

Spreitzer, G.M. (1995). Psychological empowerment in the workplace: dimensions, measurement, and validation. Academy of Management Journal, 38 (5), 1442-1465.

Spreitzer, G.M. (2005). Empowerment at work. (Working Paper Series), Michigan: Ross School of Business.

Şimşek, Ö. F. (2007). Yapısal eşitlik modellemesine giriş: temel ilkeler ve LISREL uygulamaları. Ankara: Ekinoks Yayıncılık.

Teo, T. S. and Choo, W. Y. (2001). Assessing the impact of using the internet for competitive intelligence, Information \& Management, 39(1), 67-83.

Thomas, K.W. and Velthouse, B.A. (1990). Cognitive elements of empowerment: an "interpretive" model of intrinsic task motivation. Academy of Management Review, 15 (4), 666-681.

Venter, P. and Tustin, D. (2009). The availability and use of competitive and business intelligence in South African business organisations. Southern African Business Review, 13(2), 88-117.

Viviers, W., Saayman, A. and Muller, M. L. (2005). Enhancing a competitive intelligence culture in South Africa. International Journal of Social Economics, 32(7), 576-589.

Wilkinson, A. (1998). Empowerment: theory and practice. Personnel Review, 27(1), 40-56. 
Wright, S., Bisson, C. and Duffy, A. (2013). Competitive intelligence and information technology adoption of SMEs in Turkey: diagnosing current performance and identifying barriers, Journal of Intelligence Studies in Business, 3(2), 5-29.

$\mathrm{Xu}, \mathrm{M}$. and Kaye, R. (2009). The Nature of strategic intelligence: current practice and solutions. New York, NY: Hershey.

Yıldırım, F. ve Karabey, C. N. (2016). Örgüt kültürünün yeniliğe etkisinde personel güçlendirmenin biçimlendirici rolü, Gazi Üniversitesi İktisadi ve İdari Bilimler Fakültesi Dergisi, 18(2), 426-453.

Yıldırım, F. ve Naktiyok, S. (2017). The mediating role of organizational support in the effect of transformational leadership on employee empowerment. Polish Journal of Management Studies, 16 (1), 292-303. 